\title{
Transitioning from physician to nurse practitioner
}

This article was published in the following Dove Press journal:

Journal of Multidisciplinary Healthcare

22 January 2014

Number of times this article has been viewed

\section{Monica Flowers \\ Maria Olenick \\ College of Nursing and Health Sciences, Nicole Wertheim College of Nursing and Health Sciences, Florida International University, Miami, FL, USA}

Correspondence: Monica Flowers College of Nursing and Health Sciences, Nicole Wertheim College of Nursing and Health Sciences, Foreign Physician Program, Florida International University, 3000 NE I 5 I st Street, ACII-204,

North Miami, FL 33I8I, USA

$\mathrm{Tel}+\mathrm{I} 3059194419$

$\mathrm{Fax}+\mathrm{I} 3059195209$

Emailmflower@fiu.edu
Abstract: Foreign-educated physicians (FEPs), also known as "international medical graduates", represent a rich source of potential primary-care providers. Despite their high level of medical knowledge and skills as well as ethnic and cultural diversity suited to meet the demands of patients, FEPs face many barriers in their attempt to continue to practice medicine in the USA. The program of study at Florida International University's Nicole Wertheim College of Nursing and Health Sciences provides FEPs the opportunity to have an impact on health care and continue to practice medicine in the USA by becoming nurse practitioners.

Keywords: foreign-educated physician, FEP, international medical graduate, IMG, nurse practitioner, NP

\section{Introduction}

The shortage of physicians in the USA is estimated to reach 91,000 by 2020 due to an increasing population and 32 million more Americans obtaining health insurance coverage in 2014 as a result of the Patient Protection and Affordable Care Act. ${ }^{1}$

Foreign-educated physicians (FEPs), also known as "international medical graduates" (IMGs), represent a rich source of potential primary-care providers given their high level of medical knowledge and skills, completion of prerequisite courses, and ethnic and cultural diversity suited to meet the demands of patients. ${ }^{2}$ Yet, after the passage of the 1976 Health Professions Educational Assistance Act, ${ }^{2}$ FEPs residing in the USA started facing many barriers to their attempt to continue to practice medicine - primarily with visa and testing requirements. FEPs who are not citizens or permanent residents require visas that are not only hard to obtain but also require them to produce evidence of two years of US residency. Even though the Conrad 30 Waiver Program offers J-1 physicians 30 waivers of the two-year residence requirement per state, this number is too small to significantly affect the US physician shortage. ${ }^{3}$ Additionally, testing requirements demand that FEPs pass two steps of the US Medical Licensing Examination then gain admission into a medical residency program and complete their residency before being licensed in the USA. ${ }^{4}$ Most FEPs do not successfully acquire a medical residency position, despite passing the US Medical Licensing Examination, and end up not being able to practice as a physician in the USA; instead, they are mostly found in low-paying jobs trying to make a life in this country, having few other options in the health care industry for which they are qualified. 


\section{Florida International University program for FEPs}

In lieu of these hurdles, Florida International University (FIU) offers FEPs an opportunity to become primary-care providers through their Accelerated Combined BSN/MSN Program for Foreign-Educated Physicians (FEP to BSN [Bachelor of Science in nursing]/MSN [Master of Science in nursing]) program. The accelerated curriculum allows students to obtain their MSN degree and become nurse practitioners (NPs) in eight semesters (3 years). FIU does not actively recruit FEPs from their country of origin, so there is no issue of contributing to the departure of these physicians from their native countries, or "brain drain". These FEPs come to the USA primarily for personal, social, political, and economic instability reasons, as are common among developing nations. They have no plans to return to their native countries. In most cases, it is only after an FEP has been in the USA for some time and realizes that becoming a US physician is difficult and unlikely that they decide to look for other options and are recruited into the FEP to BSN/MSN program. Generally, most of the FEPs in the BSN/MSN program have sought US medical residency for at least five years unsuccessfully prior to considering alternative options.

Most FEPs who interview and qualify for the FEP to BSN/MSN program state they are working in low-paying jobs such as medical technicians, phlebotomists, and research assistants. They refer to these jobs as ways to simply make a living in this country while the reality of not being able to practice as a licensed physician sets in and they look for other options.

According to the Association of American Medical Colleges' Center for Workforce Studies analysis of 2010, ${ }^{1}$ the demand for primary-care physicians will be 45,000 in the next decade. Data collected by the Educational Commission for Foreign Medical Graduates ${ }^{5}$ show that the top three specialties FEPs pursue are internal medicine (45.8\%), pediatrics (11.0\%), and family medicine (7.9\%). Research has found NPs are an important resource for expanding the supply of primary-care providers, ${ }^{8}$ so FEP to BSN/MSN graduates can enhance patient access to primary care in rural and urban areas.

\section{Benefits of NPs}

\section{Cost}

In addition to the physician shortage, actuaries estimate health-care spending will grow to US\$4.6 trillion annually by $2019 .{ }^{6}$ Research finds that employing NPs is more cost-effective than employing physicians. ${ }^{8}$ There are many reasons for this, with the most referenced being: the annual salary of an NP is approximately one-third that of a physician's salary; the cost of NP education is far less than that of physicians'; there is a reduction in the number of hospital days, laboratory fees, and emergency-room services associated with the use of NPs; and indirect savings are made from patients' increased accessibility to health-care services and a focus on patient-centered care and preventive medicine. ${ }^{7,8}$

\section{Quality}

Further, evidence consistently shows that NP quality of care and patient outcomes are equivalent or superior to those of physicians for comparable services they are qualified to deliver. ${ }^{7} \mathrm{NP}$ care has been shown to reduce morbidity and mortality rates as well as decrease the number of days patients lose from work. ${ }^{7}$ For patients, this means faster improvement, less time in hospital, less likelihood of complications, and better long-term health prospects. Additionally, most studies found that patients were more satisfied with NP-led care due to its more comprehensive nature, personal focus, and reduction in costs. ${ }^{8} \mathrm{NPs}$ consistently scored equal to or better than physicians in measures of interpersonal skills, communication, counseling/interviewing skills, and technical skills, and were particularly effective in enhancing patient knowledge and patient compliance. ${ }^{8}$

\section{FIU program of study}

The program of study at FIU's Nicole Wertheim College of Nursing and Health Science fast tracks FEPs through a BSN and MSN in half the time it takes traditional students. An allopathic medical doctor (MD) degree from a foreign country translates into a bachelor's degree in the USA. FEPs are given credit for previous basic science courses. The admission criteria include: a score of 550 in the Test of English as a Foreign Language (TOEFL), a test of English proficiency; assuring prerequisites have been completed; a Health Education Systems, Inc., nursing admission test; and an in-person interview. Because FEPs present with the equivalent of a previous bachelor's degree, they are able to take graduate-level courses in pathophysiology, pharmacology, research, and other content areas immediately, for which they may attain credit at both undergraduate and graduate levels in the nursing program. The program builds on FEPs' prior knowledge and experience and acclimates them to US nursing and health care. Many of the physicians in this program have stated that US nursing is much like how they practiced medicine in their countries. They are impressed with the level at which US nurses and NPs practice and feel it is a great fit for them since they come 
from countries where holistic medicine, care of the family, and care of the community are common approaches.

The first class of these unique graduates finished just recently in the summer of 2013.

\section{Description of students currently in the program}

Initially, program applicants were primarily from South Florida. However, the program now receives applicants from all over the country. Currently, there are students enrolled in the program who have relocated to Miami from Wisconsin, Texas, Maryland, California, Tennessee, Massachusetts, New York, and Illinois.

There are currently over 200 FEP students enrolled in the FEP to BSN/MSN program. The diversity of the student body continues to grow as students are admitted to the Health Resources and Services Administration grant-supported program. Approximately $95 \%$ of students come from culturally diverse minority backgrounds, with over 30 countries represented. The majority of students are from Cuba (39\%) and Haiti (28\%), while others are from Venezuela (3\%), Peru (2\%), Colombia (6\%), the Dominican Republic (3\%), India (3\%), Nigeria (2\%), Lithuania (1\%), and Ecuador (1\%). Other represented countries from which $1 \%$ or less of the student population come, include Argentina, Bangladesh, Bolivia, Bulgaria, China, Costa Rica, Italy, Mexico, Puerto Rico, Tajikistan, and the Ukraine. The median age of students in the program is 40 years (range of 24-60) and 51\% of the students are male.

Spanish is the primary native language of the FEP students, at $61 \%$, while French/Creole is the native language of $27 \%$ of the students. Other native languages of FEP students include Bulgarian, Chinese, Farsi, Igbo, Italian, Lithuanian, Nigerian, Punjabi, Limbum, Tamil, and Ukrainian.

These students are exceptionally well prepared to manage the culturally, linguistically, and generationally diverse underserved populations in the USA. The global education and experience they bring with them, along with the education and experience they gain in the USA, make them an incredible asset and a potential solution to the shortage of practitioners. This opportunity gives them the ability to reenter health care as a nurse and/or NP while also providing them with a unique inter-professional perspective.

\section{American Medical Association recommendations}

FEPs present a valuable resource to meet the physician shortage in the USA. In response to current requirements, the American Medical Association (AMA) ${ }^{9}$ recommends: increasing the number of residency positions available for FEPs, the creation of a new visa category, actively recruiting FEPs and requiring a two-year residency program in the USA, or developing a global medical education system "in which the undergraduate and graduate medical education standards of the United States shape medical education abroad", allowing FEPs to flow seamlessly between countries. Before these AMA recommendations are instituted, FEPs have the opportunity to affect health care by becoming NPs and continuing to practice in the USA.

\section{Conclusion}

Based on economic analyses and the published literature, FEPs as NPs can enhance access to quality and cost-effective health care. NPs improve access; are cost-efficient; decrease health disparities; facilitate continuity of care, increase patient satisfaction; and, in comparison to physicians, have equivalent or superior outcomes and technical quality as well as better interpersonal skills. ${ }^{7,8}$ All FEP to BSN/MSN program graduates thus far who have taken national certification board tests to become NPs have passed. Also, recruiters are very actively seeking to hire these new graduates since they have had physician, nurse, and nurse-practitioner education and training.

\section{Disclosure}

The authors declare no conflicts of interest in this work.

\section{References}

1. Association of American Medical Colleges (AAMC). Physician Shortages to Worsen without Increases in Residency Training. Washington DC: AAMC; nd. Available from: https://www.aamc.org/ download/150584/data/. Accessed May 20, 2013.

2. Grossman D, Jorda ML. Transitioning foreign-educated physicians to nurses: the New Americans in Nursing accelerated program. $J$ Nurs Educ. 2008;47(12):544-551.

3. US Citizenship and Immigration Services. Conrad 30 Waiver Program [web page on the Internet]. Washington DC: US Department of Homeland Security; nd [updated August 7, 2013]. Available from: http://www.uscis. gov/portal/site/uscis/menuitem.eb1d4c2a3e5b9ac89243c6a7543f6d1a/?v gnextoid=ce9a702c84202310 VgnVCM100000082ca60aRCRD\&vgnext channel=ce9a702c84202310VgnVCM100000082ca60aRCRD. Accessed August 13, 2013.

4. Anderson S. Doctor, doctor, why won't America let in more doctors? Forbes. December 2, 2012. Available from: http://www.forbes.com/ sites/stuartanderson/2012/12/02/doctor-doctor-why-wont-america-letin-more-doctors/. Accessed May 2, 2013.

5. Educational Commission for Foreign Medical Graduates (ECFMG). 2011 Annual Report. Philadelphia, PA: ECFMG; 2012. Available from: http:// www.ecfmg.org/resources/ECFMG-2011-annual-report.pdf. Accessed May 1, 2013.

6. CMS.gov. National health expenditure data [web page on the Internet]. Baltimore, MD: CMS.gov; nd [updated April 11, 2012]. Available from: https://www.cms.gov/nationalhealthexpenddata/03_national healthaccountsprojected.asp. Accessed May 13, 2013. 
7. Bauer JC. Nurse practitioners as an underutilized resource for health reform: evidence-based demonstrations of cost-effectiveness. J Am Acad Nurse Pract. 2010;22(4):228-231.

8. Keleher H, Parker R, Abdulwadud O, Francis K. Systematic review of the effectiveness of primary care nursing. Int J Nurs Pract. 2009;15(1): $16-24$.
9. American Medical Association (AMA). International Medical Graduates in American Medicine: Contemporary Challenges and Opportunities. Chicago, IL: AMA; 2013. Available from: http://www. ama-assn.org/resources/doc/img/international-medical-graduates-inamerican-medicine.pdf. Accessed May 13, 2013.

\section{Publish your work in this journal}

The Journal of Multidisciplinary Healthcare is an international, peerreviewed open-access journal that aims to represent and publish research in healthcare areas delivered by practitioners of different disciplines. This includes studies and reviews conducted by multidisciplinary teams as well as research which evaluates the results or conduct of such teams or health- care processes in general. The journal covers a wide range of areas and welcomes submission from practitioners at all levels, from all over the world. The manuscript management system is completely online and includes a very quick and fair peer-review system. Visit http://www.dovepress. com/testimonials.php to read real quotes from published authors.

Submit your manuscript here: http://www.dovepress.com/journal-of-multidisciplinary-healthcare-journal 